
\title{
$\begin{array}{ll}\text { Research Square } & \begin{array}{l}\text { Preprints are preliminary reports that have not undergone peer review. } \\ \text { They should not be considered conclusive, used to inform clinical practice, } \\ \text { or referenced by the media as validated information. }\end{array}\end{array}$
}

\section{Association between Blood Lead Levels and Markers of Calcium Homeostasis: A Systematic Review and Meta-Analysis}

\author{
Kuldip Upadhyay \\ National Institute of Occupational Health \\ Ankit Viramgami \\ National Institute of Occupational Health \\ Bhavani Shankara Bagepally \\ National Institute of Epidemiology \\ Rakesh Balachandar ( $\sim$ balachandar.rakesh@gmail.com) \\ National Institute of Occupational Health
}

Research Article

Keywords: Calcium homeostasis, Lead exposure, Parathyroid hormone, Vitamin D, Systematic Review

Posted Date: November 16th, 2021

DOI: https://doi.org/10.21203/rs.3.rs-1042280/v1

License: (c) (1) This work is licensed under a Creative Commons Attribution 4.0 International License. Read Full License

Version of Record: A version of this preprint was published at Scientific Reports on February 3rd, 2022. See the published version at https://doi.org/10.1038/s41598-022-05976-4. 


\section{Abstract}

\section{Introduction:}

Chronic $\mathrm{Pb}$ exposure associated systemic illness are partly posited to involve calcium homeostasis. Present systematic review aims to comprehensively evaluate the association between chronic lead exposure and markers of calcium homeostasis.

\section{Methods:}

Observational studies documenting the changes in calcium homeostasis markers (i.e. serum calcium, parathyroid hormone, vitamin D \& calcitonin) between occupationally $\mathrm{Pb}$ exposed group and control group were systematically searched from digital databases since inception to March $17,2021$. PRISMA guidelines were adhered during execution. Mean differences of calcium homeostasis markers between the groups were analysed using random-effects model. Heterogeneity was assessed by $R$ statistic, while the risk of bias was performed using Newcastle Ottawa Scale. Sub-group, sensitivity and meta-regression analyses were performed where data permitted.

\section{Results:}

Eleven studies were (837 Pb exposed vs 739 controls) identified. Pb exposed group exhibited higher mean 36.13 (95\%Cl 25.88-46.38) $\mu$ g/dl blood lead level significantly lower serum calcium, and trend of higher parathyroid levels and lower vitamin D levels than controls. Heterogeneity was high among the studies.

\section{Conclusion:}

Considering the cardinal role of calcium in multiple biological functions, present observations emphasis the need for periodic evaluation of calcium levels and its markers among those with known cumulative exposure to $\mathrm{Pb}$.

\section{Highlights}

- Systematic review confirms the association between chronic lead exposure and aberrations in calcium homeostasis markers

- Serum calcium was significantly lower among chronically lead exposed individuals as compared to control participants

- The evidence was synthesized predominantly from relatively heterogeneous and scarce high-quality primary studies

\section{Introduction}

Lead $(\mathrm{Pb})$, a common hazardous heavy metal bioaccumulates in various tissues on chronic exposure, causing serious systemic illnesses. The pathophysiology posited in some $\mathrm{Pb}$-induced health hazards involves direct and indirect interference with calcium metabolism and homeostasis. Despite studies verifying the causal role of perturbations on calcium homeostasis/metabolism is fewer; collective evidence supports the Pb-calcium interactions (1). The availability of calcium in serum for various biological functions are tightly regulated by parathyroid hormone (parathormone), calcitonin and vitamin. Therefore, parathormone, calcitonin, vitamin D, and serum calcium (itself) constitute calcium homeostasis markers (2).

Few mechanisms posited in Pb altering calcium homeostasis include the inhitoing of enzymes responsible for vitamin $\mathrm{D}$ activation (i.e., 1 ahydroxylase), thereby reducing serum calcium $(3,4)$. Given growing reports of $\mathrm{Pb}$ among the general population and inconclusive evidence from individual primary studies regarding the association of blood lead levels (BLL) on calcium homeostasis markers (parathyroid and vitamin $D)$ (5-9), there is need to investigate current evidences of association (if any) between the duo.

Individuals employed at workplaces involving $\mathrm{Pb}$ and its derivatives commonly exhibit high BLL. Hence, the present study aimed to systematically investigating the association between BLL and calcium homeostasis markers by reviewing those studies comparing calcium homeostasis markers between individuals occupationally exposed to $\mathrm{Pb}$ as against those without obvious $\mathrm{Pb}$ exposure. In addition the study aimed at exploring the association between BLL and bone resorption / turnover markers (urinary pyridinoline, urinary deoxypyridinoline, osteocalcin, osteopontin).

\section{Methods}

The study proposed to employ PRISMA (Preferred Reporting Items of Systematic reviews and Meta-Analysis) guidelines during every step of its execution (10) and the protocol was eaelier registered at PROSPERO (ID: CRD42020199503). Observational studies of both cross-sectional or longitudinal design, evaluating calcium homeostasis markers among occupationally $\mathrm{Pb}$ exposed participants as compared to those without obvious exposure were systematically searched using key terms from pubmed-Medline, Scopus, and Embase digital repositories. The key terms were constructed on the basis of PICOS approach (i.e., Participants, Intervention (exposure to Pb), Controls (obviously unexposed Pb), Outcome (calcium homeostasis markers), and Study design). Sensitivity and precision maximizing strategy was adopted to identify relevant studies. Detailed search terms and search strategies are reported in the appendix. The search was performed on September 24, 2020 (updated search in Pubmed on March 17, 2021). A lateral search was performed for potential studies using the bibliography of included studies. 
Primary literature reporting the differences in calcium homeostasis markers in otherwise healthy individuals occupationally exposed to $\mathrm{Pb}$, as compared to those without a history of occupational $\mathrm{Pb}$ exposure, were considered. Calcium homeostasis markers viz. serum calcium, vitamin $\mathrm{D}$, calcitonin, and parathyroid were primarily aimed in addition to bone resportion / turnover markers. Preclinical studies (animal/cell line), studies reporting acute $\mathrm{Pb}$ poisoning, involving individuals with congenital/acquired disorders of calcium metabolism or other endocrine disturbances, review articles, commentaries, letters to the editors, editorials, and methodology articles were excluded from the review.

Screening and reviewing of studies: Conventional screening steps of executing the systematic review, including independent screening of the title and abstract of studies, for their potential inclusion were followed by the authors (RB, KU, AV). The final list of studies meeting the inclusion-exclusion criteria for data extraction was prepared ensuring no duplication. Any conflict during the independent review was resolved by mutual consensus.

Data collection, extraction, analysis, and management: All necessary details from the primary literature vital for executing the proposed study were extracted using the data extraction form (Google sheets). The data extraction sheet included details of the participant (age, gender, and duration of employment), occupation/workplace (nature of workplace, location, simultaneous exposure to other heavy metals), and outcome measurements, in addition to details of the article (title, year of publication, journal, authors and contact details of the corresponding author) whenever available.

Data on central tendency (mean / median) and dispersion (standard deviation (SD) / Standard error (SE) / Interquartile range / 95\% confidence interval (CI)) for available parameters were independently extracted from the included studies by (AV \& RB). Webplot application (11) was used for extracting data when the results were graphically reported (12). The data after confirmation for consistency was used for further analysis. For studies reporting outcome variables other than the conventional units / standard units, the outcome parameters were converted to uniform units using standard conversion factors $(3,6)$.

When the measures of central tendency (e.g., median, mode) \& data dispersion (e.g., $95 \%$ confidence interval, interquartile range, standard error of mean) were provided (13) alternate to mean \& SD, appropriate conversions were performed (14-16). Lastly, in situations where the primary study reported more than one exposed group (7), grand mean and SD was calculated (17),

Pooled mean difference $(95 \% \mathrm{Cl})$ between the occupationally $\mathrm{Pb}$ exposed workers and the control group was estimated using the generic inverse variance method by pooling the mean and SD from individual studies. On anticipating high heterogeneity random-effects model was employed during meta-analysis (18).

Heterogeneity, sensitivity, subgroup, and Risk of Bias Assessment: The heterogeneity among included studies was assessed using visual inspection of forest plots, the Cochran-Q test, and I-squared $\left(R^{2}\right)$ statistics. The $P^{2}>25 \%$ or Cochrane- $Q<0.1$ were regarded as evidence for heterogeneity among the included studies. Further, the sources of heterogeneity were explored by fitting the co-variables (mean age, mean duration of exposure, and percentage of males in the study, whichever was available) individually in the meta-regression model when more than ten primary studies were available. A particular variable exhibiting a $50 \%$ reduction in $R^{2}$ was regarded as a potential source of heterogeneity.

Publication bias was assessed using funnel plot (asymmetry) and Egger's test $(p<0.05)$ of the effect measures $(19,20)$. Further, on identifying asymmetry in the funnel plot, the source of asymmetry was explored using a contour-enhanced funnel plot. Lastly, sensitivity \& subgroup analysis was performed to investigate the influence of the simultaneous exposure to other heavy metals (yes vs. no/not available) on the outcome variables. However, the sub-group analysis was conducted only if sufficient (i.e., $\geq 2$ ) studies were available for subgroup/sensitivity analysis. The changes in the mean difference and heterogeneity $\left(R^{2}\right)$ were considered to decide (interpret) the influence of a particular subgroup analysis (21).

Data was recorded using a Microsoft Excel sheet (version 2016) and analyzed using Stata version 16 (22). Two-sided $p<0.05$ was considered statistically significant except for the subgroup analysis and heterogeneity test, wherein $p<0.10$ was regarded as significant.

Assessment of the risk of bias in included studies: Newcastle Ottawa scale was employed independently by the authors for assessing the risk of bias in the included studies (23). Briefly, the tool was used for rating the risk of bias in participant selection, comparison of cases and controls, and assessing the exposure. Based on agreement with the definition of cases and controls in the individual studies, their representativeness and comparabality, and relatively occupational $\mathrm{Pb}$ exposure, individual studies were rated with a star(s). Any conflict in the rating was resolved by mutual consensus among the authors.

\section{Results}

The electronic search retrieved 12,430 studies. After removal of duplicates, screening of abstract \& titles of all studies, 52 of them were considered for full-text review. Full-text scrutiny resulted in eleven studies for the final quantitative data synthesis. Total number of studies excluded and the reasons are described in the PRISMA flowchart (Figure 1).

Description of studies: Details of the individual studies such as sample size, mean age of participants, duration of occupational exposure, type of industry (responsible for occupational $\mathrm{Pb}$ exposure), simultaneous exposure to other heavy metals, and the outcome parameters reported are described in table 1. Majority of the included studies reported sample mean of the outcome variables of control groups within the recommended normal values (i.e., Serum calcium: 8.2 - $10.2 \mathrm{mg} / \mathrm{dl}$, ionized Calcium: $4.60-5.08 \mathrm{mg} / \mathrm{dl}$, serum PTH: $10-65 \mathrm{pg} / \mathrm{ml}$ and vitamin D: 25 - $80 \mathrm{ng} / \mathrm{ml}$ ) (24) suggesting the control group as apparently normal in terms of the outcome parameters (24). However, the mean Vitamin D of the control group from Dongre et al. 
2013 was lower than the recommended values (7). None of the studies reported calcitonin levels, while a single study reported bone turnover/ resorption markers (5). Briefly, all studies recruited 100\% male participants, except Batra et al. 2014 (4), where 11.3\% were female participants. The sources of occupational $\mathrm{Pb}$ exposure among the exposed group vaired across $\mathrm{Pb}$ battery and its allied industries, $\mathrm{Pb}$ smelting process, e-waste recycling process, welding, and paint industries. The duration of occupational Pb exposure was not available for a majority of the studies, while few reported the exposure duration ranging from 5 to 34 years. The studies were restricted to Asian (India, China, and Bangladesh), European (Croatia, Austria, Turkey, and Israel), and African (Nigeria) countries, while no studies from Australia or American (both Latin and North) countries were available.

Risk of Bias assessment: The risk of bias during participant selection, ascertainment of exposure, and outcome parameters were evaluated using Newcastl Ottawa scale (23) (Table 2). Notable risk of bias in the participant selection included convenient sampling, inadequate representativeness of the exposed and control participants (in view of absence of precise records on exposure), non-description of precise source of control participants in some of the studies $(7,9,25)$ and incomplete description of control participants (i.e., occupation, confirmation of their non-exposure) $(4,7,9,25)$. Additionally, as the interviewer(s) were non-blinded to the participant status (as either exposed or unexposed), the exposure assessment could have been potentially biased.. Therefore, none of the included studies was comparable to that of a well-conducted RCT.

\section{Meta-analysis results of individual outcome parameters}

Blood lead levels: Current systematic search identified eleven studies that reported BLL among occupationally Pb exposed \& control workers (3-9, 12, $13,25,26)$. All identified studies reported significantly $(\mathrm{p}<0.05)$ higher BLL among occupationally exposed workers as compared to control subjects. The results were congruent with the current pooled quantitative analysis, wherein individuals with occupational exposure to $\mathrm{Pb}$ had a mean $\mathrm{BLL}$ of $36.13 \mu \mathrm{g} / \mathrm{dl}(95 \% \mathrm{Cl}, 25.88$ to $46.38, R=99.75 \%, \mathrm{p}<0.05)$ higher than controls (Figure 2$)$. Subgroup analysis of studies involving $\mathrm{Pb}$ exposed participants with history of co- exposure to other heavy metal(s) did not alter the results (Supplement Figure 1). Explorative uni-variate meta-regression with participants' mean age as the moderator did not significantly reduce the heterogeneity / alter results. Further, the assymteric funnel plot suggests publication bias $(p=0.425)$, while the contour enhanced funnel plot suggests the presence of other biases as well. (Supplement Figure2).

Urinary lead levels: Two studies reported Urine Pb levels among occupationally $\mathrm{Pb}$ exposed \& unexposed workers. The pooled mean difference between the groups was $10.89 \mu \mathrm{g} / \mathrm{dl}\left(95 \% \mathrm{Cl},-1.01\right.$ to $\left.22.79, \mathrm{I}^{2}=96.71\right)$. Subgroup, meta-regression and funnel plot analysis were not possible in view of fewer studies.

Serum calcium: Ten of the included studies reported serum calcium levels, while seven of them observed significantly lower calcium levels among occupationally $\mathrm{Pb}$ exposed group compared to control group $(3,4,6-9,12,13,25,26)$. The $\mathrm{Pb}$ exposed group exhibited $-0.72 \mathrm{mg} / \mathrm{dl}(95 \% \mathrm{Cl}-0.36 \mathrm{to}$ $-1.07, P=95.12 \%$ ) lower calcium levels as compared to the control group. (Figure $3 \mathrm{~A}$ ). Subgroup analysis of studies involving Pb exposed participants with a history of co-exposure to other heavy metal(s), did not significantly reduce the heterogeneity, however reduced the magnitude of the difference between the duo $(-0.39 \mathrm{mg} / \mathrm{dl}, 95 \% \mathrm{Cl}-0.64$ to $-0.15, P=72.04 \%)(3,6,8,12,13)$ (Supplement Figure 3$)$. Meta-regression analysis with participant's mean age as moderator, did not significantly change the results. Further, the assymetric funnel plot was suggestive of publication bias $(p=0.779)$ and the contour enhanced funnel plot suggested the presence of other biases as well (Supplement Figure 4).

Serum ionized Calcium: Four of the included studies reported ionized serum calcium levels. All but one study reported statistically significant lower ionized calcium levels among occupationally $\mathrm{Pb}$ exposed group compared to control group $(3,7,8,26)$. The results were consistent with that of the serum calcium levels, i.e., the pooled mean difference revealed lower ionized calcium levels among occupationally $\mathrm{Pb}$ exposed group as compared to the control group $(-1.20 \mathrm{mg} / \mathrm{dl}$ with $95 \% \mathrm{Cl}-2.38$ to -0.02 and $R=99.76 \%)$ (Figure 3B). In view of limited studies, subgroup, meta-regression and funnel plot analysis were not executed.

Parathyroid hormone (PTH) (Paratharmone): Five included studies reported parathormone levels; all but one observed lower serum PTH levels among occupationally $\mathrm{Pb}$ exposed as compared to the control group $(4,5,7,8,26)$. Occupationally $\mathrm{Pb}$ exposed group exhibited mean $37.97 \mathrm{pg} / \mathrm{ml}(95 \% \mathrm{Cl}$ -14.36 to 90.29 and $R=99.80 \%$ ) lower parathormone levels as compared the control group, with high levels of heterogeneity (Figure $4 \mathrm{~A}$ ). However, the results were statistically not significant. Subgroup and meta-regression analyses weren't taken up, given fewer available studies reporting parathormone levels.

Vitamin D: Five studies reported Vitamin D levels, and all but one reported significantly lower Vitamin $\mathrm{D}$ levels among occupationally Pb exposed group compared to control group $(4,5,7,8,25,26)$. The pooled mean difference between the duo was $-12.26(95 \% \mathrm{Cl}-25.36$ to $0.84, P=99.10 \%) \mathrm{ng} / \mathrm{dl}$ with high heterogeneity (Figure $4 \mathrm{~B}$ ). Although the results indicate the point estimate of the effect measure for Vitamin $\mathrm{D}$ was lower among Pb exposed, the result was statistically not significant. Due to the limited number of studies, subgroup and meta-regression analysis were not executed.

Calcitriol: Two of the included studies reported differences in calcitriol levels (active form of vitamin D), with one study reporting higher (8) while the the other (5) reported contrastingly lower serum calcitriol levels among occupationally $\mathrm{Pb}$ exposed group compared to control group. The pooled mean difference between the duo was -5.98 ( $95 \% \mathrm{Cl}-8.40$ to $20.35, R=91.20 \%) \mathrm{pg} / \mathrm{dl}$ with high heterogeneity. The results are suggestive of lower calcitriol among $\mathrm{Pb}$-exposed as compared to the control group; however, the result was statistically not significant. Due to a limited number of studies, subgroup and meta-regression analysis were not carried out. 
Other outcome parameters: Akbar et al. (2014) alone compared serum osteocalcin (bone resorption marker), urinary deoxypyridinoline, and urinary hydroxyproline values between the two groups(5). Both bone turnover markers in urine (deoxypyridinoline and hydroxyproline) and bone resorption markers (osteocalcin) were higher among the $\mathrm{Pb}$ exposed as compared to the non-exposed control; however, the results of urinary bone turnover markers (deoxypyridinoline and hydroxyproline) were statistically significant $(p<0.05)$.

\section{Discussion}

Present study systematically pooled existing evidence to determine the association between occupational Pb exposure and calcium homeostasis markers. Therefore studies comparing calcium homeostasis markers among occupationally Pb exposed workers as against unexposed control participants were systemically reviewed. Salient observations include, chronic Pb exposure (mostly occupational) was associated with derangement of calcium homeostasis markers. However, these observations were derived by pooling relatively heterogeneous studies.

Occupationally $\mathrm{Pb}$ exposed workers exhibited significantly higher $\mathrm{BLL}$ as compared to control participants without a history of occupational $\mathrm{Pb}$ exposure. The results were supported by most of the included studies irrespective of the duration of exposure or type of workplace employed. Interestingly, the occupationally unexposed subjects too had $\mathrm{Pb}$ in their blood, however with significantly lower levels as compared to exposed participants. As Pb has no known biological functions, there was no absolutely safe / recommended BLL. Though the average acceptable BLLs among the general population earlier documented was 1.2 micrograms/dl (27), however, based on observations from the "Adult Blood Lead Epidemiology and Surveillance" program, the Center for Disease Control has relaxed the levels and designated < 10 micrograms/dl as reference levels for adults (28). Surprisingly six of the eleven included studies reported mean BLL $>10$ micrograms/dl among the unexposed control group $(3,6,7,12,26)$. Reasons for such high BLL among the control group was possibly with exposure to environmental Pb contributed by leaded fuel, Pb-based paints, leaded plumbings, etc. Considering the potential hazardous nature of $\mathrm{Pb}$ and no known physiological role, the possible sources of environmental $\mathrm{Pb}$ exposure should be meticulously investigated and control strategies to be employed.

Pooled results suggest the occupational $\mathrm{Pb}$ exposure was significantly associated with lower serum calcium (total Calcium and ionized Calcium) and a trend of higher parathormone and lower vitamin D levels. Current observations require cautious interpretation, in view of results being synthesized by pooling relatively heterogeneous primary literature (unacceptably high heterogeneity i.e., $P>95 \%$ ), probably biased by publication bias as inferred by the funnel plots. Lastly, for fewer primary studies in this regard, meta-regression, subgroup, and sensitivity analyses were restricted.

Lead, a biochemical analogue of calcium, was posited to impair the activation of vitamin D (i.e., formation of calcitriol) and thereby perturbs calcium metabolism (i.e., reduction in serum calcium) $(3,4)$. Parathormone, known to regulate the serum calcium levels by feedback mechanisms, was in turn elevated by lower calcium levels. Consistent with the posited mechanisms, occupationally Pb exposed individuals exhibited significantly lower serum calcium levels and trend of higher parathormone levels and lowered vitamin D levels in the present study. Based on current observations and previous inferences confirming the association between chronic $\mathrm{Pb}$ exposure and reduced prolactin levels, $\mathrm{Pb}$ may be regarded as an endocrine disruptor (29).

Observations from the present study was perhaps the earliest to confirm the association between occupational Pb exposure and derangement in calcium homeostasis markers (particularly calcium) via systematic review and meta-analysis. However, the limitations inherent to systematically pooling results from primary literature such as heterogeneity among them, absence of high-powered studies, non-uniform reporting of results, and other unknown factors, should be considered while interpreting the current results. Future longitudinal studies, investigating the role of vitamin $D$ intervention in alleviating the aberrations in the calcium homeostasis markers and estimating the bone turnover/resorption markers would throw more light in this regard. In view of the vitality of the trace element (Calcium) in physiologic functions (viz. musculoskeletal system and second messenger) and the influence of parathormone on bones (calcium mobilization to regulate serum calcium), current study recommends their evaluation as part of the periodic worker examination protocol in occupationally $\mathrm{Pb}$ exposed workers.

Conclusion: Current results support the inverse relationship between chronic $\mathrm{Pb}$ exposure and calcium homeostasis markers (particularly reduction in serum calcium). However, considering the lack of evidence from high-quality studies, further evidences from multicentred longitudinal studies, including additional investigations (vitamin D metabolites, bone turnover/ resorption markers) is warranted for a precise understanding of the relation between the duo. Present observations perhaps suggest the need to draft regulations for periodic examination of calcium homeostasis markers among those chronically exposed to lead.

\section{Declarations}

\section{Data availability statement:}

Not applicable,

\section{Funding statement:}

No funding support for this work 


\section{Conflict of interest disclosure:}

None

\section{Ethics approval statement:}

Not applicable

\section{Patient consent form:}

Not applicable

\section{Any other permissions:}

Not applicable

\section{Acknowledgments:}

None

\section{Authors Contribution:}

UpadhyayK: Conceptualization, Data curation, Investigation, Methodology and Review.

Viramgami A: Conceptualization, Data curation, Investigation, Methodology, Original draft and Review

Bagepally BS. Data curation, Formal analysis, Investigation, Methodology, Software, Original draft \& Review.

Balachandar R: Conceptualization, Data curation, Investigation, Methodology, Original draft \& Review.

\section{References}

1. Pounds JG. Effect of lead intoxication on calcium homeostasis and calcium-mediated cell function: a review. Neurotoxicology. 1984;5(3):295-331.

2. Medicine) Ilo. Dietary Reference Intakes for Calcium and Vitamin D. In: Ross AC, Taylor CL, Yaktine AL, Del Valle HB, editors. Dietary Reference Intakes for Calcium and Vitamin D. Washington (DC): The National Academies Press; 2011.

3. Anetor J I ATS, Adeniyi F A, Taylor G O. Decreased. Decreased total and ionized calcium levels and haematological indices in occupational lead exposure as evidence of the endocrine disruptive effect of lead. Indian Journal of Occupational \& Environmental Medicine. 2005;9:7.

4. Batra J, Thakur A, Meena SK, Singh L, Kumar J, Juyal D. Blood lead levels among the occupationally exposed workers and its effect on calcium and vitamin D metabolism: A case-control study. J Family Med Prim Care. 2020;9(5):2388-93.

5. Akbal A, Tutkun E, Yilmaz H. Lead exposure is a risk for worsening bone mineral density in middle-aged male workers. Aging Male. 2014;17(3):18993.

6. Anetor JI, Ajose OA, Adebiyi JA, Akingbola TS, lyanda AA, Ebesunu MO, et al. Decreased thiamine and magnesium levels in the potentiation of the neurotoxicity of lead in occupational lead exposure. Biol Trace Elem Res. 2007;116(1):43-51.

7. Dongre NN, Suryakar AN, Patil AJ, Hundekari IA, Devarnavadagi BB. Biochemical effects of lead exposure on battery manufacture workers with reference to blood pressure, calcium metabolism and bone mineral density. Indian J Clin Biochem. 2013;28(1):65-70.

8. Kristal-Boneh E, Froom P, Yerushalmi N, Harari G, Ribak J. Calcitropic hormones and occupational lead exposure. Am J Epidemiol. 1998;147(5):458-63.

9. Osterode W, Ulberth F. Increased concentration of arachidonic acid in erythrocyte membranes in chronically lead-exposed men. J Toxicol Environ Health A. 2000;59(2):87-95

10. Moher D, Liberati A, Tetzlaff J, Altman DG, Group P. Preferred reporting items for systematic reviews and meta-analyses: the PRISMA statement. J Clin Epidemiol. 2009;62(10):1006-12.

11. Rohatgi A. WebPlotDigitalizer: HTML5 based online tool to extract numerical data from plot images. 3 ed2012

12. Wang Y, Sun X, Fang L, Li K, Yang P, Du L, et al. Genomic instability in adult men involved in processing electronic waste in Northern China. Environ Int. 2018;117:69-81. 
13. Pizent A, Jurasovic J, Telisman S. Serum calcium, zinc, and copper in relation to biomarkers of lead and cadmium in men. J Trace Elem Med Biol. 2003;17(3):199-205.

14. Hozo SP, Djulbegovic B, Hozo I. Estimating the mean and variance from the median, range, and the size of a sample. BMC Med Res Methodol. 2005;5:13.

15. Luo D, Wan X, Liu J, Tong T. Optimally estimating the sample mean from the sample size, median, mid-range, and/or mid-quartile range. Statistical Methods in Medical Research. 2018;27(6):1785-805.

16. Wan X, Wang W, Liu J, Tong T. Estimating the sample mean and standard deviation from the sample size, median, range and/or interquartile range. BMC Medical Research Methodology. 2014;14(1):135.

17. Altman DG MD, ; Bryant TN; Gardner MJ. Statistics with Confidence, Second Edition: BMJ Books; 2000.

18. DerSimonian R, Laird N. Meta-analysis in clinical trials revisited. Contemp Clin Trials. 2015;45(Pt A):139-45.

19. Deeks JJ, Altman DG. Effect Measures for Meta-Analysis of Trials with Binary Outcomes. Systematic Reviews in Health Care2001. p. 313-35.

20. Egger M, Davey Smith G, Schneider M, Minder C. Bias in meta-analysis detected by a simple, graphical test. BMJ. 1997;315(7109):629-34.

21. Higgins JPT TJ, Chandler J, Cumpston M, Li T, Page MJ,. Cochrane Handbook for Systematic Reviews of Interventions version 6.0. July 2019.

22. StataCorp. . Stata Statistical Software Release 16. College Station, TX: StataCorp LLC.; 2019.

23. Wells G SB, O'Connell D, Peterson J, Welch V, Losos M, Tugwell P. The Newcastle-Ottawa Scale (NOS) for assessing the quality of nonrandomised studies in meta-analyses Ottawa2013

24. values Lr. Lab reference values [updated 5th Jan 2020. Available from:https://education.endocrine.org/system/files/ESAP\%202015\%20Laboratory\%20Reference\%20Ranges.pdf.

25. Himani, Kumar R, Ansari JA, Mahdi AA, Sharma D, Karunanand B, et al. Blood Lead Levels in Occupationally Exposed Workers Involved in Battery Factories of Delhi-NCR Region: Effect on Vitamin D and Calcium Metabolism. Indian J Clin Biochem. 2020;35(1):80-7.

26. Mazumdar I, Goswami K, Ali MS. Status of Serum Calcium, Vitamin D and Parathyroid Hormone and Hematological Indices Among Lead Exposed Jewelry Workers in Dhaka, Bangladesh. Indian J Clin Biochem. 2017;32(1):110-6.

27. CDC lead document. CDC web document 2015 [cited 2015. Available from:https://www.cdc.gov/niosh/topics/ables/pdfs/Reference\%20Blood\%20Levels\%20for\%20Adults-2015-12-18_508.pdf.

28. Centers for Disease C, Prevention. Very high blood lead levels among adults - United States, 2002-2011. MMWR Morb Mortal Wkly Rep. 2013;62(47):967-71.

29. Balachandar R, Bagepally BS, Kalahasthi R, Haridoss M. Blood lead levels and male reproductive hormones: A systematic review and metaanalysis. Toxicology. 2020;443:152574.

\section{Tables}

Table 1

Description of the studies 


\begin{tabular}{|c|c|c|c|c|c|c|c|}
\hline Study & Country & $\begin{array}{l}\text { Outcome } \\
\text { parameters } \\
\text { reported }\end{array}$ & $\begin{array}{l}\text { Sample Size } \\
\text { (n) } \\
\text { [Exposed: } \\
\text { controls] }\end{array}$ & $\begin{array}{l}\text { Age in years } \\
\text { (mean } \pm \text { SD) } \\
\text { [Exposed Vs } \\
\text { Controls] }\end{array}$ & $\begin{array}{l}\text { Duration of Pb } \\
\text { exposure (in } \\
\text { years) [mean } \pm \\
\text { SD] }\end{array}$ & $\begin{array}{l}\text { Exposure to } \\
\text { other heavy } \\
\text { metals }\end{array}$ & Industry type of exposed \\
\hline \multirow{2}{*}{$\begin{array}{l}\text { Akbalet al } \\
\text { (2014) (5) }\end{array}$} & \multirow[t]{2}{*}{ Turkey } & \multirow{2}{*}{$\begin{array}{l}\text { PTH, } \\
\text { Calcitriol, } \\
\text { UDP* HYP* } \\
\text { and OC }\end{array}$} & \multirow[t]{2}{*}{$30: 32$} & $39.4 \pm 8.7$ vs & \multirow[t]{2}{*}{ NA } & \multirow[t]{2}{*}{ NA } & \multirow[t]{2}{*}{ Lead batteries, } \\
\hline & & & & $37.9 \pm 8.2$ & & & \\
\hline $\begin{array}{l}\text { Anetor et al } \\
(2005)(3)\end{array}$ & Nigeria & $\mathrm{Ca}^{*}$ & $86: 51$ & NA & NA & Copper & Lead factory \\
\hline \multirow{3}{*}{$\begin{array}{l}\text { Anetor et al } \\
(2007)(6)\end{array}$} & \multirow[t]{3}{*}{ Nigeria } & \multirow[t]{3}{*}{$\mathrm{Ca}$} & \multirow[t]{3}{*}{$47: 25$} & $33.0 \pm 8.2$ & \multirow[t]{3}{*}{ NA } & \multirow[t]{3}{*}{ Magnesium } & \multirow{3}{*}{$\begin{array}{l}\text { Welding }(n=9) \text {, Printing } \\
(n=10) \text {, Paint }(n=14) \\
\text { and Battery }(n=14)\end{array}$} \\
\hline & & & & Vs. & & & \\
\hline & & & & $36.0 \pm 2.5$ & & & \\
\hline \multirow{3}{*}{$\begin{array}{l}\text { Batra et al } \\
(2020)(4)\end{array}$} & \multirow[t]{3}{*}{ India } & \multirow{3}{*}{$\begin{array}{l}\mathrm{Ca}^{\star}, \mathrm{PTH}^{\star}, \\
\text { Vit-D* }\end{array}$} & \multirow[t]{3}{*}{$80: 80$} & $30.9 \pm 5.75$ & \multirow[t]{3}{*}{$8.57 \pm 3.81$} & \multirow[t]{3}{*}{ NA } & \multirow[t]{3}{*}{ Lead battery } \\
\hline & & & & Vs. & & & \\
\hline & & & & $30.2 \pm 6.01$ & & & \\
\hline $\begin{array}{l}\text { Dongre et al } \\
(2013)(7)\end{array}$ & India & $\begin{array}{l}\text { Ca, PTH, } \\
\text { Vit-D }\end{array}$ & $90: 30$ & Range: 20 to 45 & $\begin{array}{l}30 \text { each with 1-5, } \\
6-10 \text { and }>10 \\
\text { years }\end{array}$ & NA & Lead battery \\
\hline \multirow{3}{*}{$\begin{array}{l}\text { Estela Kristal } \\
\text { Boneh et al } \\
\text { (1998) (8) }\end{array}$} & \multirow[t]{3}{*}{ Israel } & \multirow{3}{*}{$\begin{array}{l}\text { Ca, PTH, } \\
\text { Vit-D, } \\
\text { Calcitriol* }\end{array}$} & \multirow[t]{3}{*}{$56: 90$} & & \multirow[t]{3}{*}{$5.3 \pm 4.0$} & \multirow[t]{3}{*}{ Magnesium } & \multirow[t]{3}{*}{$\begin{array}{l}\text { Lead battery and } \\
\text { recycling }\end{array}$} \\
\hline & & & & Vs. & & & \\
\hline & & & & $41.5 \pm 9.3$ & & & \\
\hline \multirow{3}{*}{$\begin{array}{l}\text { Himani et al } \\
\text { (2018) (25) }\end{array}$} & \multirow[t]{3}{*}{ India } & \multirow[t]{3}{*}{$\mathrm{Ca}^{*}$, Vit-D* } & $100: 100$ & $32.6 \pm 10.3$ & $14.8 \pm 9.5$ & NA & Lead battery \\
\hline & & & & Vs. & & & \\
\hline & & & & $34.7 \pm 7.9$ & & & \\
\hline $\begin{array}{l}\text { Mazumderet } \\
\text { al } \\
(2016)(26)\end{array}$ & Bangladesh & $\begin{array}{l}\text { Ca*,PTH*, } \\
\text { Vit-D* }\end{array}$ & $47: 42$ & NA & NA & NA & Jewellery \\
\hline Osteroid et al & Austria & $\mathrm{Ca}$ & $12: 12$ & $42.8 \pm 5.0$ & NA & NA & $\mathrm{Pb}$ smelting \\
\hline & & & & Vs. & & & \\
\hline & & & & $40.1 \pm 5.0$ & & & \\
\hline Pizent et al & Croatia & $\mathrm{Ca}^{*}$ & $143: 156$ & 34.0 & 8 (range 2-34) & Cadmium & Lead battery \\
\hline & & & & Vs. & & & \\
\hline & & & & 35.0 & & & \\
\hline Wang et al & China & $\mathrm{Ca}^{*}$ & $146: 121$ & 35.8 & NA & Copper & Electronic waste \\
\hline & & & & Vs. & & & \\
\hline & & & & 34.9 & & & \\
\hline $\begin{array}{l}\text { Ca-Calcium, } \\
\text { deoxypyridin }\end{array}$ & $\begin{array}{l}\text { P- hydroxy } \\
\text { e, Vit-D -V }\end{array}$ & $\begin{array}{l}\text { oline, NA-I } \\
\text { min D }\end{array}$ & available, & C- osteocalcine, & [-parathyroid ho & mone, UDP & Urinary \\
\hline
\end{tabular}

Table 2

Newcastle Ottawa scale for assessing the risk of bias in the included studies. 


\begin{tabular}{|c|c|c|c|c|c|c|c|c|c|}
\hline & $\begin{array}{l}\text { Adequacy } \\
\text { of case } \\
\text { definition }\end{array}$ & $\begin{array}{l}\text { Case } \\
\text { representativeness }\end{array}$ & $\begin{array}{l}\text { Selection } \\
\text { of } \\
\text { controls }\end{array}$ & $\begin{array}{l}\text { Definition } \\
\text { of } \\
\text { controls }\end{array}$ & $\begin{array}{l}\text { Comparability } \\
\text { of groups }\end{array}$ & $\begin{array}{l}\text { Ascertainment } \\
\text { of exposure }\end{array}$ & $\begin{array}{l}\text { Similarity in } \\
\text { the method of } \\
\text { ascertainment }\end{array}$ & $\begin{array}{l}\text { Non- } \\
\text { response } \\
\text { rate }\end{array}$ & Total* \\
\hline $\begin{array}{l}\text { Akbal et al } \\
2014(5)\end{array}$ & * & - & * & * & * & * & - & - & 5 \\
\hline $\begin{array}{l}\text { Anetor et } \\
\text { al } \\
2005 \text { (3) }\end{array}$ & - & - & * & * & * & - & * & - & 4 \\
\hline $\begin{array}{l}\text { Anetor et } \\
\text { al 2007(6) }\end{array}$ & - & - & * & * & $\star *$ & - & * & - & 5 \\
\hline $\begin{array}{l}\text { Batra et al } \\
2020(4)\end{array}$ & - & - & * & - & $\star \star$ & - & * & - & 4 \\
\hline $\begin{array}{l}\text { Dongre et } \\
\text { al 2013(7) }\end{array}$ & - & - & - & - & - & - & * & - & 1 \\
\hline $\begin{array}{l}\text { Estela } \\
\text { Kristal } \\
\text { Boneh et } \\
\text { al } \\
1998 \text { (8) }\end{array}$ & - & * & * & * & - & - & * & * & 5 \\
\hline $\begin{array}{l}\text { Himani et } \\
\text { al } \\
2020(25)\end{array}$ & - & - & - & - & * & - & * & - & 2 \\
\hline $\begin{array}{l}\text { Mazumder } \\
\text { et al } \\
2016(26)\end{array}$ & - & - & * & * & - & - & * & - & 3 \\
\hline $\begin{array}{l}\text { Osteroid et } \\
\text { al } \\
2010 \text { (9) }\end{array}$ & - & - & - & - & - & - & * & - & 1 \\
\hline $\begin{array}{l}\text { Pizent et } \\
\text { al } \\
2003 \text { (13) }\end{array}$ & - & * & * & * & * & - & * & * & 6 \\
\hline $\begin{array}{l}\text { Wang et al } \\
2018(12)\end{array}$ & - & - & * & * & $\star \star$ & - & * & - & 5 \\
\hline
\end{tabular}

\section{Figures}




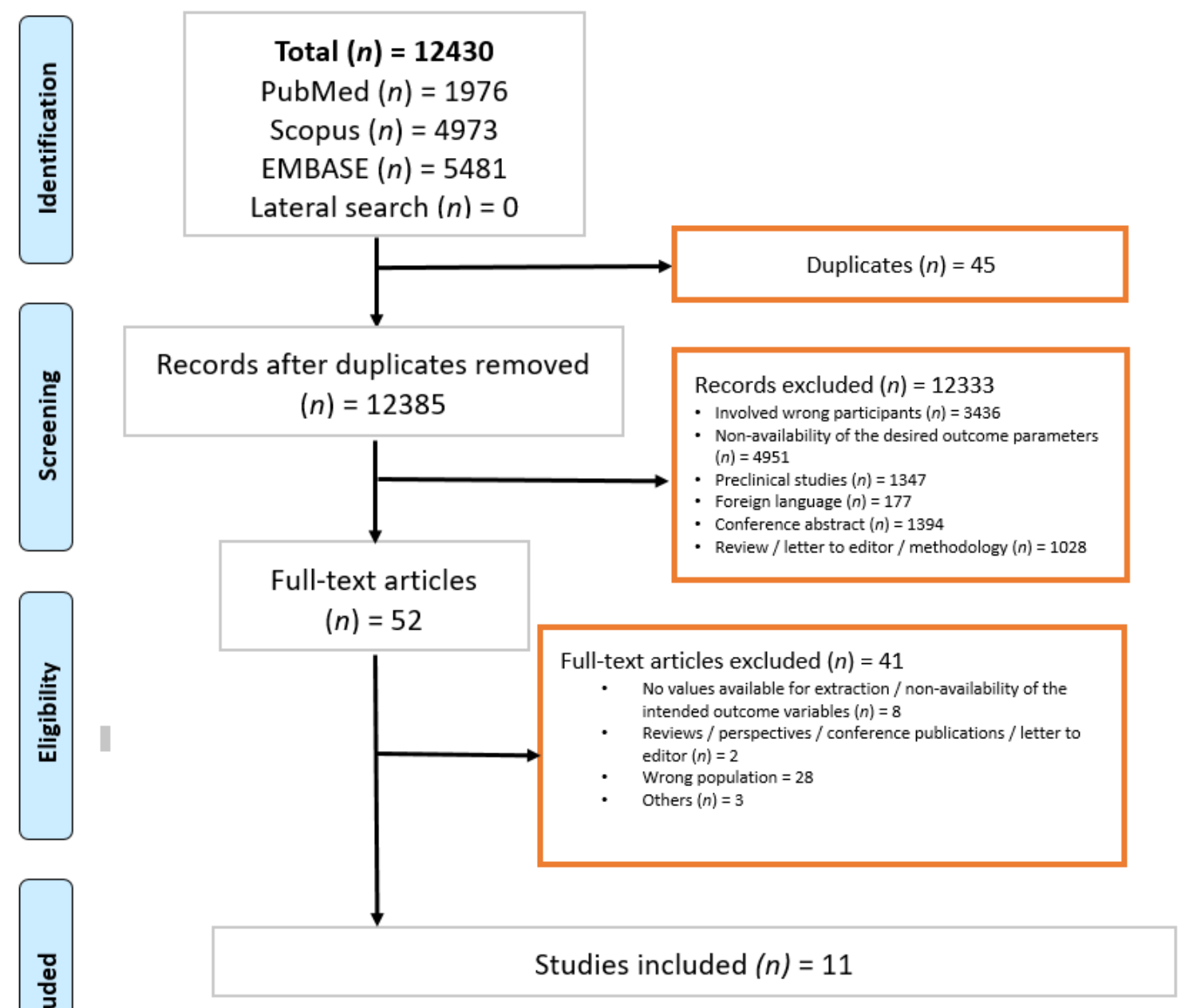

- $\operatorname{BLL}(n)=11 \quad \bullet \operatorname{PTH}(n)=5 \quad \bullet$ Vitamin $\mathrm{D}(n)=5$

- Serum / blood calcium $(n)=10 \quad \bullet$ Serum ionized Ca $(n)=4$

\section{Figure 1}

PRISMA flow chart Legends: The flow chart illustrates the number of articles included and excluded at various steps 
Blood Lead Levels

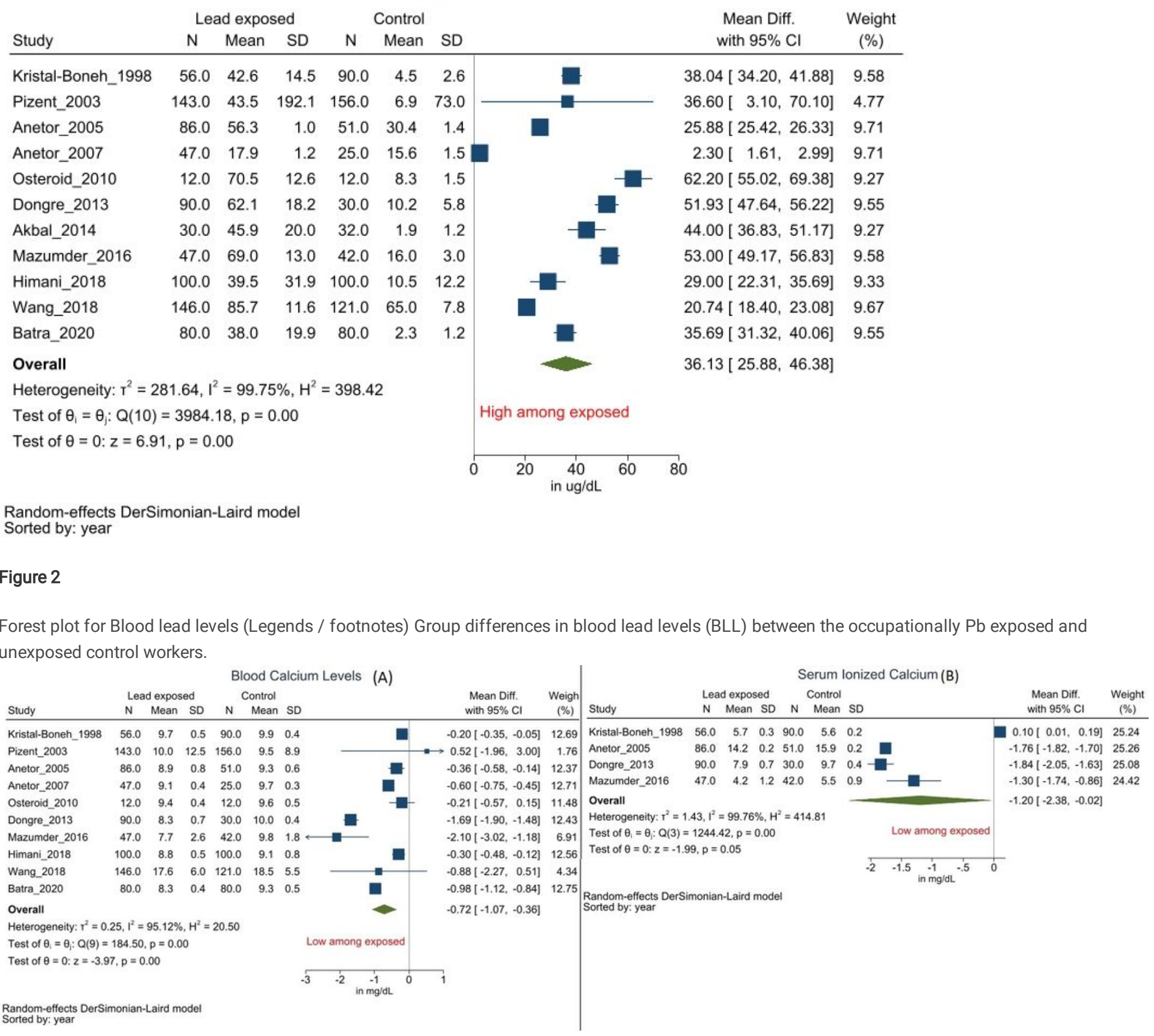

\section{Figure 3}

Forest Plot for blood calcium (Legends / footnotes) Group differences in serum calcium (A) and Inonized Calcium (B) between the occupationally Pb exposed and unexposed control workers.

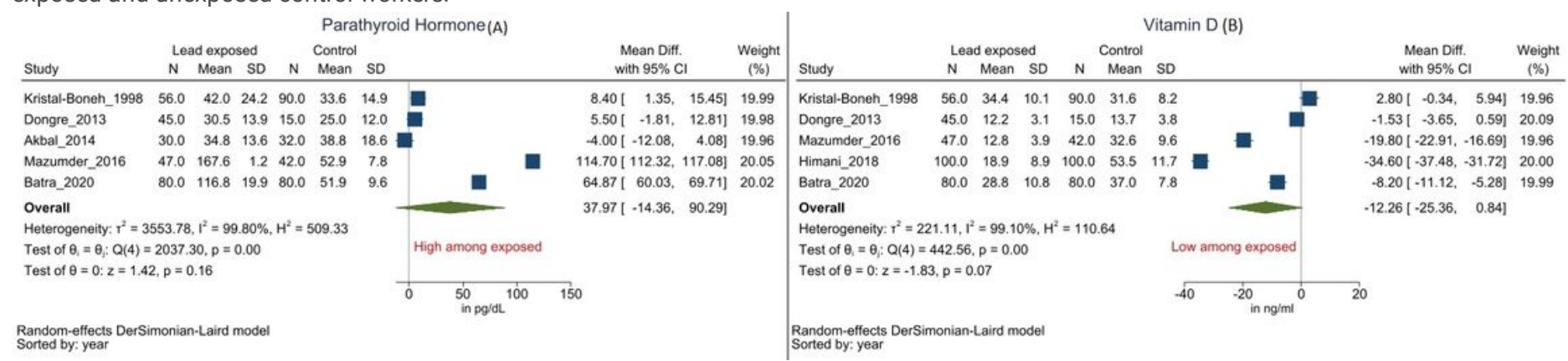

Figure 4 
Forest Plot for parathormone (A) and Vitamin D (B) (Legends / footnotes) Group differences in paratharmone (A) and vitamin D (B) between the occupationally $\mathrm{Pb}$ exposed and unexposed control workers.

\section{Supplementary Files}

This is a list of supplementary files associated with this preprint. Click to download.

- SupplementaryMaterial.pdf 